\title{
Evaluation of the Correlation between the Vertical Dimension of Occlusion and the Length of the Ear, Nose, and Little Finger: An Anthropometric Study
}

\author{
1Janhavi J Rege, ${ }^{2}$ Sulekha S Gosavi, ${ }^{3}$ Siddharth Y Gosavi, ${ }^{4}$ Shivsagar Tewary, ${ }^{5}$ Abhijeet Kore
}

\begin{abstract}
Introduction: The aim of this study was to find out the anthropometric correlation of vertical dimension of occlusion (VDO) with the length of ear, nose, and little finger in dentate male and female subjects in Karad population, so as to use this correlation to determine VDO in edentulous patients.

Materials and methods: The study was conducted in Krishna Institute of Medical Sciences Deemed University, Karad, India, on 320 dentate subjects (160 males and 160 females) who fulfilled the inclusion criteria. Anthropometric measurements of VDO, length of ear, length of nose, and length of little finger were recorded using a digital vernier caliper. Simple linear regression model was used to develop a prediction formula for VDO using length of ear, nose, and little finger as the independent variable. Correlation between VDO and length of ear, nose, and little finger was studied using Pearson's correlation test.
\end{abstract}

Results: Statistical analysis in male and female subjects showed that VDO is significantly different with the length of nose, ear, and little finger. Pearson correlation test showed VDO in males has strong coefficient correlation with the length of the ear $(r=0.500)$, and strong coefficient correlation with the length of the nose $(r=0.335)$ in females.

Conclusion: The regression analysis was conducted to formulate the regression equation for determination of VDO in male and female subjects. The study revealed that the length of ear in males [VDO $=25.591+0.565$ (length of ear)] and the length of nose in females [VDO $=36.933+0.353$ (length of nose)] are strongly correlated with VDO.

Clinical significance: The regression formulae were formulated for male and female subjects in dentate patients which can be used to determine the VDO in edentulous patients.

Keywords: Anthropometry, Ear length, Little finger length, Nose length, Vertical dimension of occlusion.

How to cite this article: Rege JJ, Gosavi SS, Gosavi SY, Tewary S, Kore A. Evaluation of the Correlation between the Vertical Dimension of Occlusion and the Length of the Ear, Nose,

\footnotetext{
${ }^{1,5}$ Associate Professor, ${ }^{2}$ Student, ${ }^{3}$ Professor, ${ }^{4}$ Assistant Professor

${ }^{1-5}$ Department of Prosthodontics, Krishna School of Dental Sciences, Krishna Institute of Medical Sciences Deemed University, Karad, Maharashtra, India

Corresponding Author: Siddharth Y Gosavi, Professor Department of Prosthodontics, Krishna School of Dental Sciences, Krishna Institute of Medical Sciences Deemed University, Karad, Maharashtra, India, Phone: +917709535768 e-mail: siddhu_gosavi@rediimail.com
}

and Little Finger: An Anthropometric Study. Int J Prosthodont Restor Dent 2017;7(1):1-7.

Source of support: Nil

Conflict of interest: None

\section{INTRODUCTION}

The accurate determination of the vertical jaw relation is extremely important in achieving successful prosthodontic therapy for function, esthetics, and comfort to the edentulous patients. The procedure of vertical relation forms the basis of all the prosthetic rehabilitation procedures, though the treatment modalities in prosthodontics has changed from removable to fixed prostheses due to rising popularity of implants. ${ }^{1}$ Many techniques have been used for measurement of the vertical dimension of occlusion (VDO), but there is no universally accepted or completely accurate method. ${ }^{2}$ It should be satisfactory to the dentist and the patient from an esthetic point of view and not induce degenerative changes from a functional standpoint. Although there are a number of different approaches in use, it is generally acknowledged by experienced prosthodontists that there is no precise scientific method of determining the correct occlusal vertical dimension. The acceptability of any vertical dimension determination depends largely upon the skill, experience, and judgment of the prosthodontist. Thus, a need exists for a reliable method for accurately determining vertical dimension to facilitate dental restorations. ${ }^{3}$ Vertical relation or vertical dimension refers to the degree of separation between the mandible, or lower jaw-bone and the maxillae, or upper jaw-bone. ${ }^{3}$ An appreciable increase or decrease in the vertical dimension of the mandible to the maxillae may cause problems in masticatory performance and speech. Deviations in vertical dimension may also cause temporomandibular joint disorders, which are often accompanied by severe physical discomfort in the jaw and neck regions. In certain cases, soreness of the supporting tissues may result, making the jaw region a target for rapid bone resorption. ${ }^{4}$ The determination of the correct vertical ramus osteotomy for edentulous patients is a fundamental problem in dentistry. Existing methods of determining the vertical relation of occlusion do not give dentists sufficiently reliable results. 
Fabrication of prosthesis for a completely edentulous patient from scratch has been proved to be a hectic process not only for the clinician but also for the patient. Various techniques have been proposed to determine the correct VDO using different measurements. Presently, vertical dimension is measured based on physiologic references, such as physiological rest position, phonetics, swallowing threshold, and mechanical methods, such as use of preextraction records and ridge parallelism. ${ }^{5-9}$ There is a need to create an alternative method to acquire the VDO, which is not only feasible for the clinician but also for the patient. Many authors used various anthropometric measurements to correlate with VDO like fingers, interpupillary distance, hairline to eyebrow line, center of pupil of right eye to center of pupil of left eye, and outer canthus of right eye to the inner canthus of right eye, distance between ear-eye to chin-nose. ${ }^{10-19}$ If an anthropometric correlation is found between the VDO and certain parameters which are easily accessible to the clinician and are static, the time taken for this procedure could be significantly reduced. Also, the conclusions would be objective for every clinician. Since the readings are specific for the particular individual, it can be easily reproducible from time to time.

Accuracy and repeatability of the measurement are considered the best criteria in selecting the best method to use. The ability of the technique to adjust, the type, and complexity of the equipment needed and the time taken to document the measurement also have to be considered. ${ }^{18}$

The present study provides a reliable method for accurately determining VDO, based on an anatomical correlation that has been found to exist between certain measurable craniofacial features. Hence, this study was carried out, in which using the golden proportion of face, the VDO was correlated with the length of ear, nose, and little finger in order to look into the possibility of designing an alternative method for determining the VDO.

\section{MATERIALS AND METHODS}

After acquiring ethical approval from the Krishna Institute of Medical Sciences University Institutional review board, 320 dentate subjects (160 males and 160 females) in the age of 19 to 25 years were selected for the study. The subjects were students of Krishna Institute of Medical Sciences, Karad, India, and the patients reporting to the same institute. To participate in this research project, the subjects had to meet the following inclusion criteria: Should have all the teeth with Angles class I molar relationship having periodontally sound teeth in both the jaws. Subjects having temperomandibular joint disorders, attrition, history of trauma, history of orthodontic treatment, and deformity of fingers, nose, and ear were excluded from the study.
Before commencing the study, clearance from the Ethical Committee was acquired. Before starting the study, subjects were given detailed information about the procedure, and those willing to participate were included in the study. Anthropometric measurements of the VDO and length of ear, nose, and little finger were recorded using a digital vernier caliper with an accuracy of $0.01 \mathrm{~mm}$.

The subjects were asked to be seated on the dental chair with proper head and back support. The height of the dental chair was adjusted to a position wherein the mandible of the subject was about $15 \mathrm{~cm}$ above the elbow level of the operator. The subject was asked to look straight and head was adjusted such that the mandible was parallel to the floor. By standing in front of the subject, the readings were recorded. Markings were made on the tip of chin, i.e., the mental protuberance and the base of nasal septum, with an indelible pencil. To record the VDO, the subject was asked to lightly bite on the posterior teeth in occlusion. Readings were noted by keeping the upper tip of the digital caliper placed at the base of the nasal septum and the lower tip was placed at the tip of the chin (mental protuberance) (Fig. 1).

For the length of nose, the glabella and most prominent part on the tip of the nose were marked with an indelible pencil. Maintaining the position of the patient, length of the nose (LNose) was measured from the glabella to the tip of the nose. The reading on the caliper was noted (Fig. 2).

For proper visibility of right ear, subject was asked to tilt his/her neck on left side so that the right ear had a better visibility and comfortable accessibility for measurement. Length of the (L Ear) ear was measured from the highest point on curvature of the helix to the lowest point on border of the lobule. The reading on the caliper was noted (Fig. 3).

To measure the length of little finger, the subject was then asked to keep his/her right hand on flat surface of the table. Placing the hand in straight, flat, and supine position,

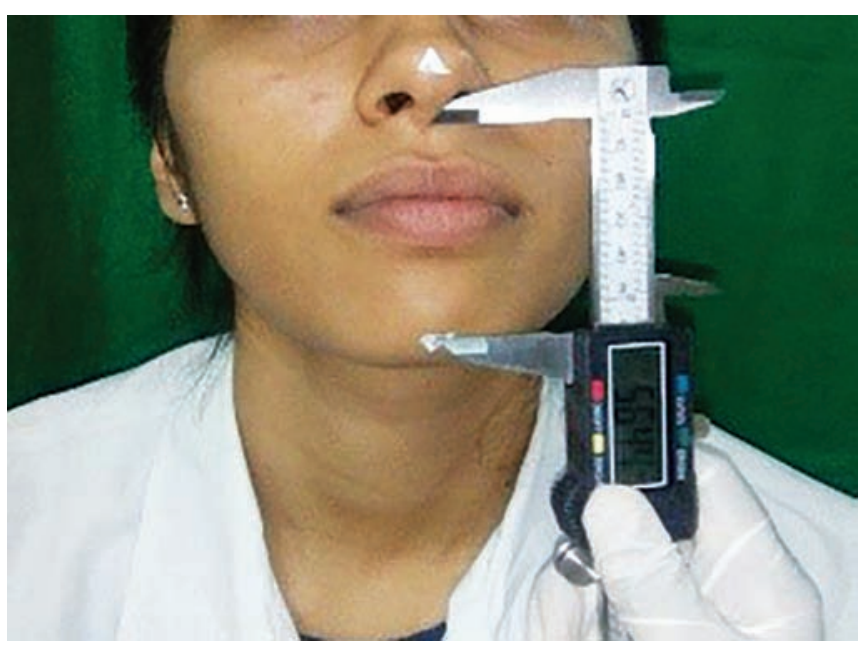

Fig. 1: Measuring VDO 


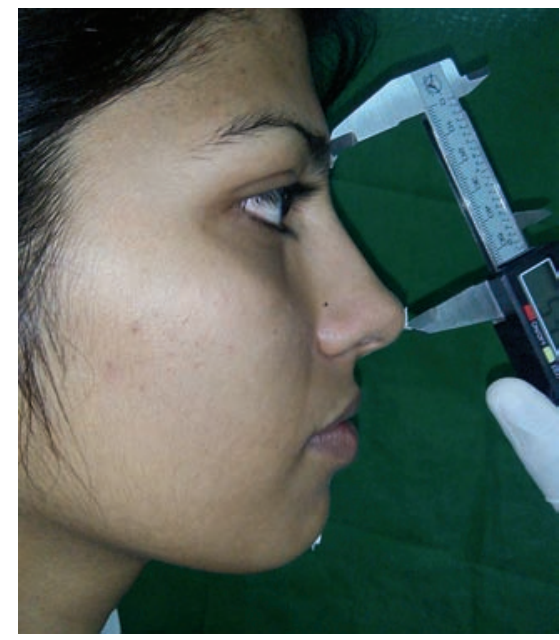

Fig. 2: Measuring length of nose

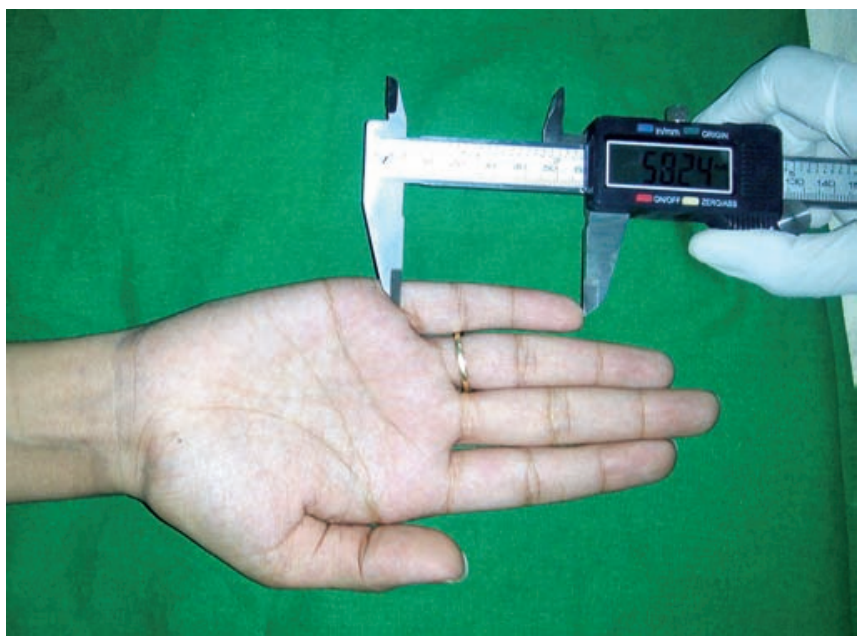

Fig. 4: Measuring length of little finger

the length of the little finger (LL Finger) was measured from tip of finger to the farther most point on palmer digital crease. The reading on the caliper was noted (Fig. 4).

Similarly, readings were taken by following the above-mentioned procedure for all the remaining 319 subjects. These readings were used as data to calculate the mean, standard deviation (SD), and standard error for all the parameters. Data were statistically analyzed using Pearson's correlation test used to find the association between the VDO and the length of nose, length of ear, and length of little finger ( $\alpha=0.01$, two-tailed).

\section{RESULTS}

The measurements of VDO, ear, nose, and little finger were recorded using a digital vernier caliper. The correlation between VDO and length of ear, nose, and little finger was statistically analyzed. The mean, SD, and statistical significance at $\mathrm{p}<0.001$ data of all subjects are depicted in Table 1. There is a statistical difference between VDO of males and females. It also shows a statistical significance between VDO and the length of ear, nose, and little finger.

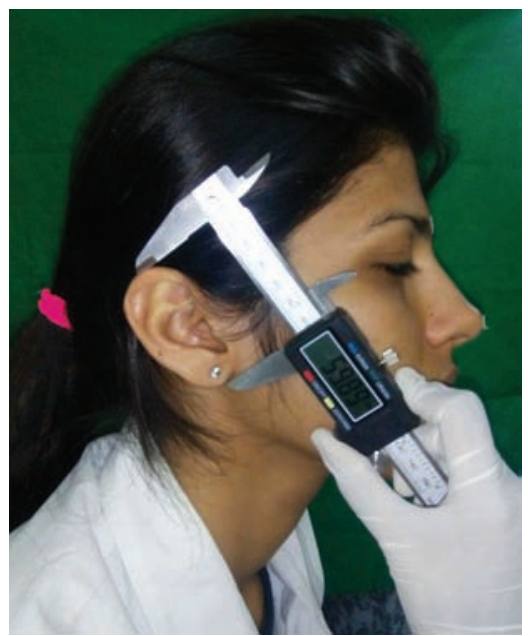

Fig. 3: Measuring length of ear

In males, the VDO has range varying from 46.140 to $73.180 \mathrm{~mm}$, with mean value of $59.415 \mathrm{~mm}$ and SD of $4.987 \mathrm{~mm}$. In females, the VDO has range varying from 43.360 to $70.830 \mathrm{~mm}$, with mean value of $55.347 \mathrm{~mm}$ and SD of $4.819 \mathrm{~mm}$.

$\mathrm{T}$ test for equality of means of males and females reveals that there was a significant difference between measurement of VDO for males and females $(t=7.419$, p-value $<0.001$ ) (Table 1 ).

In males, the length of nose has range varying from 36.840 to $71.290 \mathrm{~mm}$, with mean value of $55.522 \mathrm{~mm}$ and $\mathrm{SD}$ of $6.147 \mathrm{~mm}$. In females, the length of nose has range varying from 40.900 to $63.120 \mathrm{~mm}$, with mean value of $52.103 \mathrm{~mm}$ and SD of $4.564 \mathrm{~mm}$ (Table 1).

$\mathrm{T}$ test for equality of means of males and females reveals that there was a significant difference between measurement of length of nose for males and females $(t=5.648$, p-value $<0.001)$ (Table 1$)$.

In males, the length of ear has range varying from 49.380 to $71.300 \mathrm{~mm}$, with mean value of $59.868 \mathrm{~mm}$ and $\mathrm{SD}$ of $4.412 \mathrm{~mm}$. In females, the length of ear has range varying from 45.750 to $68.830 \mathrm{~mm}$, with mean value of $56.971 \mathrm{~mm}$ and SD of $3.925 \mathrm{~mm}$.

$\mathrm{T}$ test for equality of means of males and females reveals that there was a significant difference between measurement of length of ear for males and females $(t=6.206$, $p$-value $<0.001$ ) (Table 1 ).

In males, the length of little finger has range varying from 39.160 to $71.340 \mathrm{~mm}$, with mean value of $58.927 \mathrm{~mm}$ and SD of $5.310 \mathrm{~mm}$. In females, the length of little finger has range varying from 40.010 to $64.550 \mathrm{~mm}$, with mean value of $54.306 \mathrm{~mm}$ and SD of $3.708 \mathrm{~mm}$.

$\mathrm{T}$ test for equality of means of males and females reveals that there was a significant difference between measurement of length of little finger for males and females $(t=9.026$, $p$-value $<0.001)$ (Table 1$)$. 
Table 1: Descriptive statistics of VDO and length of nose, ear, and little finger for males and females

\begin{tabular}{lllllllll}
\hline Measurements & Factor & $n$ & Mean & SD & Minimum & Maximum & $t$-test statistic & Sig. \\
\hline Vertical dimension of occlusion & Male & 160 & 59.415 & 4.987 & 46.140 & 73.180 & 7.419 & 0 \\
& Female & 160 & 55.347 & 4.819 & 43.360 & 70.830 & & \\
L Nose & Male & 160 & 55.522 & 6.147 & 36.840 & 71.290 & 5.648 & 0 \\
& Female & 160 & 52.103 & 4.564 & 40.900 & 63.120 & & \\
L Ear & Male & 160 & 59.868 & 4.412 & 49.380 & 71.300 & 6.206 & 0 \\
& Female & 160 & 56.971 & 3.925 & 45.750 & 68.830 & & \\
LL Finger & Male & 160 & 58.927 & 5.310 & 39.160 & 71.340 & 9.026 & 0 \\
Vertical dimension of occlusion & Female & 160 & 54.306 & 3.708 & 40.010 & 64.550 & & - \\
L Nose & All & 320 & 57.381 & 5.303 & 43.360 & 73.180 & - & - \\
L Ear & All & 320 & 53.812 & 5.670 & 36.840 & 71.290 & - & - \\
LL Finger & All & 320 & 58.420 & 4.414 & 45.750 & 71.300 & - & - \\
\hline
\end{tabular}

Table 2: Correlations of VDO with Length of nose, length of ear, and length of little finger in males

\begin{tabular}{|c|c|c|c|c|c|}
\hline Males & Statistic & Vertical dimension of occlusion & L nose & Lear & LL finger \\
\hline \multirow[t]{2}{*}{ Vertical dimension of occlusion } & Pearson correlation & 1 & 0.471 & 0.500 & 0.232 \\
\hline & Sig. (2-tailed) & & 0 ** & 0 ** & $0.003^{\star *}$ \\
\hline \multirow[t]{2}{*}{ L Nose } & Pearson correlation & 0.471 & 1 & 0.329 & 0.263 \\
\hline & Sig. (2-tailed) & 0 ** & & 0 ** & $0.001^{* *}$ \\
\hline \multirow[t]{2}{*}{ L Ear } & Pearson correlation & 0.500 & 0.329 & 1 & 0.395 \\
\hline & Sig. (2-tailed) & $0^{* *}$ & $0^{* *}$ & & $0^{* *}$ \\
\hline \multirow[t]{2}{*}{ LL Finger } & Pearson correlation & 0.232 & 0.263 & 0.395 & 1 \\
\hline & Sig. (2-tailed) & $0.003^{\star *}$ & $0.001^{\star *}$ & 0 ** & \\
\hline
\end{tabular}

${ }^{* *}$ Correlation is significant at 0.01 level (2-tailed)

The correlation coefficient of VDO with length of ear, nose, and little finger for male subjects is separately shown in Table 2. Statistical analysis in male subjects showed that VDO is significantly different with the length of nose, ear, and little finger. Pearson correlation test shows more coefficient correlation with the length of the ear $(0.500)$ as compared with the length of nose (0.471) and length of little finger (0.232), which suggests that the length of ear is more closer to the VDO in males (Table 2).

Graphs 1 to 3 show Pearson correlation test for males in relation to VDO with length of nose, VDO with length of ear, and VDO with length of little finger respectively.
The correlation equations for VDO in relation with nose, ear, and little finger in males are:

- Vertical dimension of occlusion $=38.192+0.382$ (length of nose) (Graph 1)

- Vertical dimension of occlusion $=25.591+0.565$ (length of ear) (Graph 2)

- Vertical dimension of occlusion $=46.559+0.218$ (length of little finger) (Graph 3)

- Vertical dimension of occlusion $=17.748+0.279$ (length of nose) +0.437 (length of ear)

- Vertical dimension of occlusion $=33.133+0.357$ (length of nose) +0.190 (length of little finger)

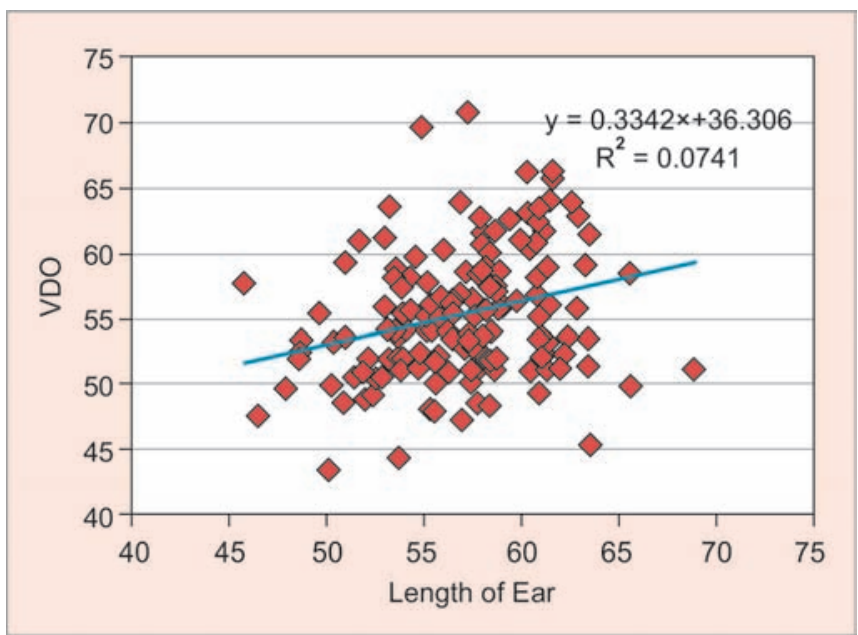

Graph 2: Correlation of length of ear in males

Graph 1: Correlation of length of nose in males 


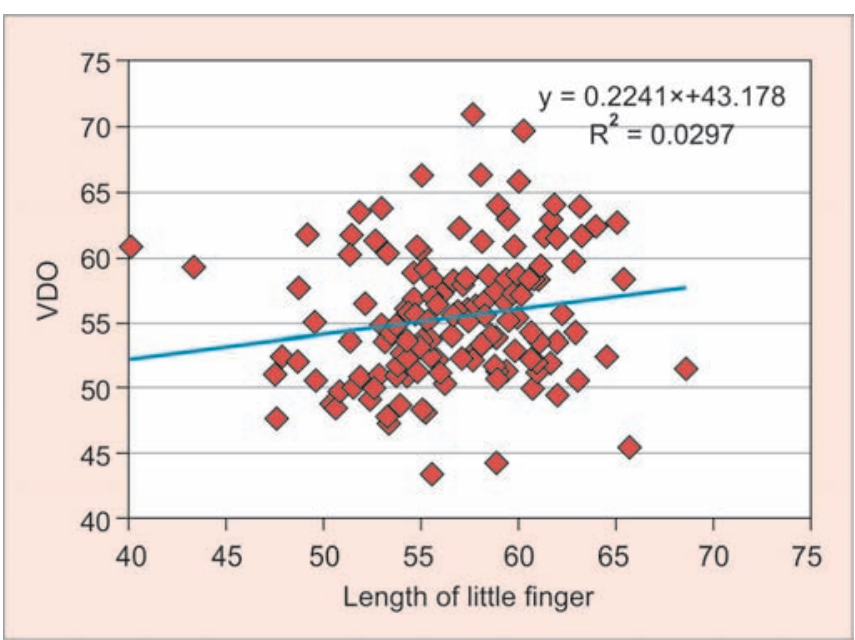

Graph 3: Correlation of length of finger in males

- Vertical dimension of occlusion $=24.409+0.547$ (length of ear) +0.039 (length of little finger)

- Vertical dimension of occlusion $=18.085+0.281$ (length of nose) +0.442 (length of ear) -0.013 (length of little finger)

The correlation coefficient of VDO with length of ear, nose, and little finger only for female subjects is shown in Table 3. Statistical analysis in female subjects showed that VDO is significantly different with the length of nose, ear, and little finger. Pearson correlation test shows more coefficient correlation with the length of the nose (0.335) as compared with the length of ear (0.272) and length of little finger (0.172), which suggests that the length of nose is closer to the VDO in females (Table 3).

Graphs 4 to 6 show Pearson correlation test for females in relation to VDO with length of nose, VDO with length of ear, and VDO with length of little finger respectively. The correlation equations for VDO in relation with nose, ear, and little finger in females are:

- Vertical dimension of occlusion $=36.933+0.353$ (length of nose) (Graph 4)

- Vertical dimension of occlusion $=36.306+0.334$ (length of ear) (Graph 5)

- Vertical dimension of occlusion $=43.178+0.224$ (length of little finger) (Graph 6)

- Vertical dimension of occlusion $=21.627+0.326$ (length of nose) +0.293 (length of ear)

- Vertical dimension of occlusion $=30.813+0.329$ (length of nose) +0.136 (length of little finger)

- Vertical dimension of occlusion $=32.614+0.297$ (length of ear) +0.108 (length of little finger)

- Vertical dimension of occlusion $=20.917+0.323$ (length of nose) +0.285 (length of ear) +0.026 (length of little finger)

Table 3: Correlations of VDO with Length of nose, length of ear, and length of little finger in females

\begin{tabular}{llllll}
\hline Females & Statistic & Vertical dimension of occlusion & L nose & L ear & LL finger \\
\hline Vertical dimension of occlusion & Pearson correlation & 1 & 0.335 & 0.272 & 0.172 \\
& Sig. (2-tailed) & & $0^{*}$ & $0^{*}$ & $0.029^{*}$ \\
L Nose & Pearson correlation & 0.335 & 1 & 0.107 & 0.218 \\
& Sig. (2-tailed) & $0^{*}$ & & 0.176 & $0.006^{*}$ \\
L Ear & Pearson correlation & 0.272 & 0.107 & 1 & 0.371 \\
& Sig. (2-tailed) & $0^{*}$ & 0.176 & 0.371 & 1 \\
LL Finger & Pearson correlation & 0.172 & 0.218 & 0.371 \\
& Sig. (2-tailed) & $0.029^{*}$ & $0.006^{*}$ & $0^{*}$ & \\
\hline
\end{tabular}

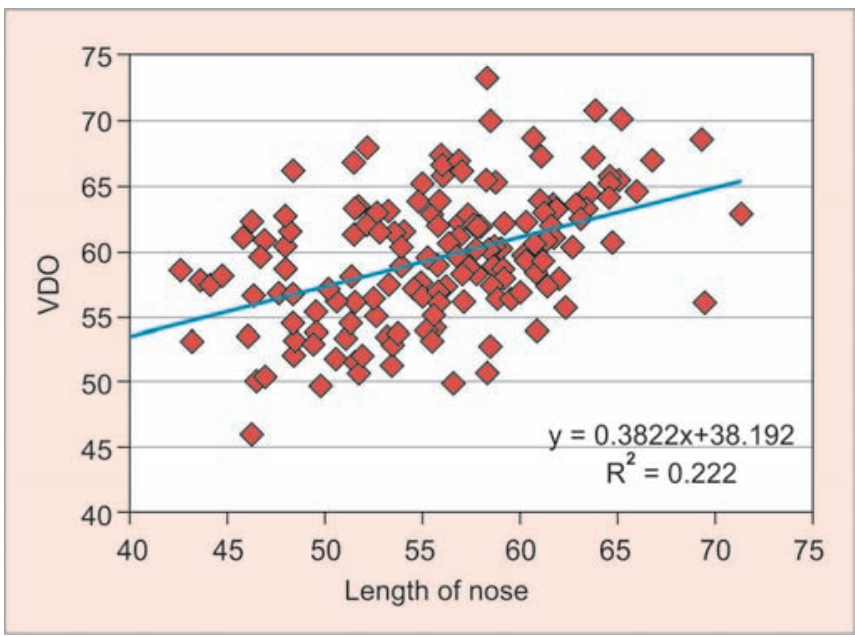

Graph 4: Correlation of length of nose in females

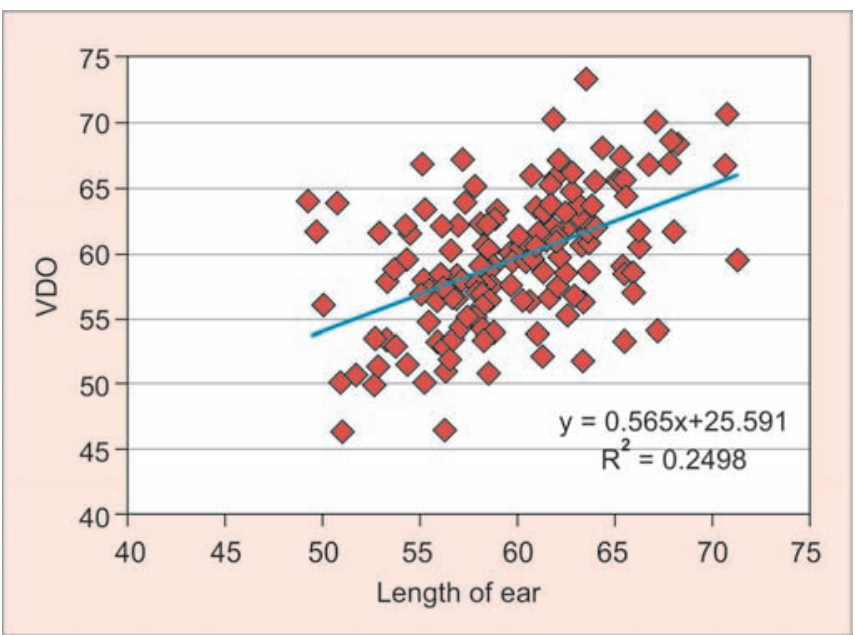

Graph 5: Correlation of length of ear in females 


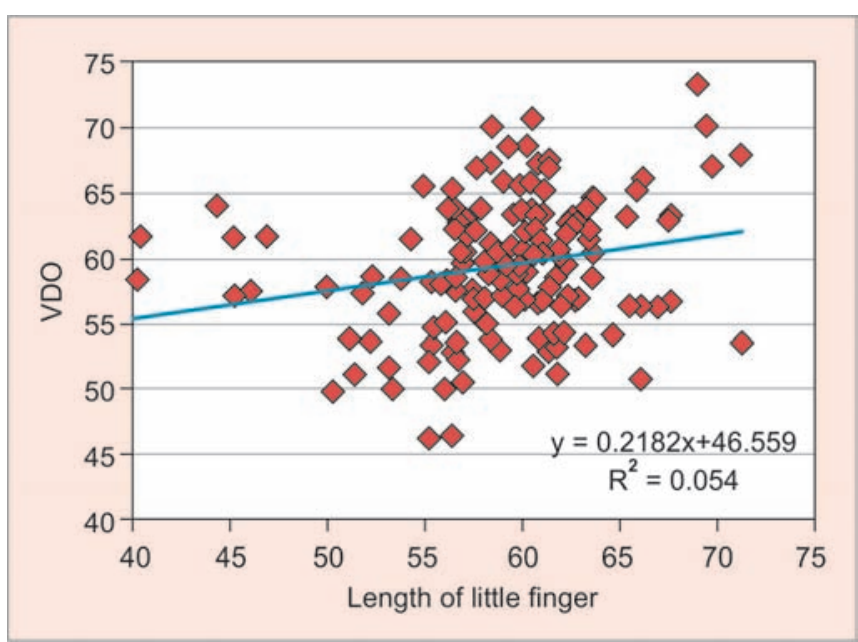

Graph 6: Correlation of length of finger in females

\section{DISCUSSION}

The sense of satisfaction on receiving complete denture prosthesis is evident on the patient's face as well as the clinician's on delivering it. A major part of this satisfaction is attributed to the enhanced esthetics of the patient and the overall prognosis of the treatment. Establishing a correct VDO has an impact on both these objectives.

Till date, many methods have been described for determining the VDO. Most of them had subjective conclusions. The subjective methods included evaluation of esthetics, phonetics, swallowing threshold, and patient comfort. The conclusions attained through them varied from clinician to clinician and lacked scientific evidence. The objective methods comprised of electromyographical records, biting power, and the utilization of facial measurements. Though the conclusions obtained through them were fruitful, the devices required to carry out the procedures were complex and cannot be routinely used. ${ }^{13}$

$\mathrm{McGee}^{20}$ found that methods which relied upon the patient's muscular perception tended to register a reduced VDO because patients felt more comfortable in that position. Silverman ${ }^{21}$ placed tattoos on alveolar ridges prior to removal of natural teeth to be used as reference points when the patient became edentulous. The distance between the markings when the teeth were in centric occlusion was measured with a pair of calipers and recorded for future use. But, patients may not accept placing of tattoos on gingiva. Smith ${ }^{22}$ stated that the Boos bimeter was the best device because it was a simple and reliable device for determining vertical dimension of rest position. However, the bimeter has been condemned, as the closing power of the patient is influenced by pain and apprehension.

To overcome these hurdles, a study was carried out to evaluate if at all any correlation exists between the
VDO and static parameters like length of ear, nose, and little finger.

The length of little finger measured in this study showed a mean of $58.927 \mathrm{~mm}$ in males and $54.306 \mathrm{~mm}$ in females. This was in accordance with the findings of Bhandari et $\mathrm{al}^{11}$ who showed a mean value of $60.57 \mathrm{~mm}$ in males and $56.224 \mathrm{~mm}$ in females. It was also in accordance with the findings of $\mathrm{Nag}$ et $\mathrm{al}^{23}$ who showed a mean value of $56.3 \mathrm{~mm}$ in females. Kalra et $\mathrm{a}^{16}$ in their study found a correlation between VDO and length of little finger in females with a mean value of $56.3 \mathrm{~mm}$ in females and a mean value of $61.5 \mathrm{~mm}$ in males.

The length of nose, i.e., from glabella to the anterior nasal spine (tip of nose), measured showed a mean of $55.522 \mathrm{~mm}$ in males and $52.103 \mathrm{~mm}$ in females. In a similar study conducted by Nagpal et $\mathrm{al}^{14}$ of measuring dimension from glabella to the subnasion (base of nose), they found the relation of this dimension with VDO was not significant. In our study, measurement was taken from tip of the nose instead of the base of the nose, so the distance measured was slightly less, which might be the reason for getting a correlation of length of nose and VDO. The Pearson correlation in the present study of VDO and length of nose in females showed a value of 0.335 , which suggested a remarkable significance of VDO with length of nose in females.

There is no study till date which correlated length of ear with VDO. In this study, correlation of VDO with the length of ear was studied to get a mean value of 59.868 $\mathrm{mm}$ in males and $56.971 \mathrm{~mm}$ in females. The Pearson correlation of VDO and length of ear in males showed a value of 0.500 , which suggested a highly significant association of VDO with length of ear in males. Therefore, the length of ear can be used as an adjunct for determination of VDO in males and length of nose in females, which is patient specific and reliable. The regression equation is developed to get the VDO.

The loss of teeth and, consequently, the provision of full prosthetic dentures have always generated great interest, for patients as well as for professionals who work in the area. This is attributable mainly to the fact that non-reestablishment of the height of the lower third of the face significantly compromises function, facial esthetics, and, consequently, the stomatognathic system, thus influencing the patient's quality of life. ${ }^{24}$ In clinical practice, there is no specific or accurate method of determining the exact vertical relation of occlusion..$^{25}$ The present study attempted to develop a methodology that could be applicable to any adult individual, regardless of gender or ethnicity. The present method is simple, alluring, convenient, noninvasive, and consistent. It does not require special training or mastering the technique; also, values are reproducible for future reference. 


\section{LIMITATIONS}

The limitation of this study was that it was conducted on small group having Angles class I molar relationship and other class of occlusions were not considered. So the findings cannot be applied on the population of other ethnic group having different types of occlusion. To endorse or refute the findings of these studies, it recommends carrying out further studies as large clinical research program to construct proper regression equation acknowledged worldwide.

\section{CONCLUSION}

This study clearly showed that the length of ear in males and the length of nose in females can be used as a measurement to determine VDO in edentulous patients. The above-mentioned regression model can also be used to determine VDO in edentulous patients with the help of length of ear, length of nose, and length of little finger.

\section{CLINICAL SIGNIFICANCE}

The landmarks used in the present study can be used more reliably since the dimensions of these will not change for the rest of the life of the individual, unless traumatized or pathologically involved. Parameters are easily accessible to the clinician and are static so that the time taken for estimating the exact VDO could be significantly reduced.

\section{REFERENCES}

1. Majeed MI, Malik A, Afzal M. Determination of occlusal vertical dimension by correlating hand, thumb and index finger length with craniofacial measurements. Med Forum 2015 Feb;26(2):8-11.

2. Al-Dhaher HA, AL-Huwaizi AF. Determination of the vertical dimension by cranio-facial measurement using clinical and cephalometric analysis (comparative study). J Bagh Coll Dent 2009;21(4):44-47.

3. Millet C, Leterme A, Jeannin C, Jaudoin P. Vertical dimension in complete denture. Rev Stomat Chiru Maxfac 2010 NovDec;111(5-6):315-330.

4. Fayz F, Eslami A. Determination of occlusal vertical dimension: a literature review. J Prosthet Dent 1998 Mar;59(3):321-323.

5. Brar A, Mattoo, Khurshid A, Singh Y, Singh M, Khurana P, Singh PR. Clinical reliability of different facial measurements in determining vertical dimension of occlusion in dentulous and edentulous subjects. Int J Prosthet Rest Dent 2014 JulSep;4(3):68-77.

6. Thompson JR, Brodie AG. Factors in the position of mandible. J Am Dent Assoc 1942 Jun;29(7):925-941.

7. Silverman MM. The speaking method in establishing the vertical dimension. J Prosthet Dent 1953 Mar;3(2):193-199.
8. Pyott JE, Schaeffer A. Centric relation and vertical dimension by cephalometric roentgenograms. J Prosthet Dent 1954 Jan;4(1):35-41.

9. Turner LC. The profile tracer: method for obtaining accurate pre-extraction records. J Prosthet Dent 1969 Apr;21(4):364-370.

10. Ciftçi Y, Kocadereli I, Canay S, Senyilmaz P. Cephalometric evaluation of maxillomandibular relationships in patients wearing complete dentures: a pilot study. Angle Orthod 2005 Sep;75(5):821-825.

11. Bhandari AJ, Ladda R, Bhandari AJ. Correlation between vertical dimension of occlusion and length of little finger. Pravara Med Rev 2012 Dec;4(4):10-14.

12. Ladda R, Bhandari AJ, Kassat VO, Angadi GS. A new technique to determine vertical dimension of occlusion from anthropometric measurements of fingers. Indian J Dent Res 2013 May-Jun;24(3):316-320.

13. Ladda R, Kasat VO, Bhandari AJ. A new technique to determine vertical dimension of occlusion from Anthropometric measurement of inter-pupillary distance. J Clin Exp Dent 2014 Oct;6(4):e395-e399.

14. Nagpal A, Prakash H, Bhargava A, Chittaranjan B. Reliability of different facial measurements for determination of vertical dimension of occlusion in edentulous using accepted facial dimensions recorded from dentulous subjects. J Indian Prosthodont Soc 2014 Sep;14(3):233-242.

15. Basnet BB, Parajuli PK, Singh RK, Suwal P, Shrestha P, Baral D. An anthropometric study to evaluate the correlation between the occlusal vertical dimension and length of thumb. Clin Cosmet Investig Dent 2015 Feb;7:33-39.

16. Kalra D, Kalra A, Goel S. Determination of the vertical dimension of occlusion from anthropometric measurements of fingers - an in vivo study. Int J Enhanced Res Med Dent Care 2015 Feb;2(2):10-15.

17. Majeed MI, Afzal M, Kashif M. Determination of occlusal vertical dimension in a section of Pakistani population using craniofacial measurements. JUMDC 2015 Jan-Mar;6(1):1-5.

18. Morais ECC, Ornaghi BP,SponchiadoAP,ZielakJC, da Costa RG, Bindo MJF, de Campos EA. Determination of final occlusal vertical dimension by cephalometric analysis. Rev Sul Bras Odont 2015 Apr-Jun;12(2):143-150.

19. Bhat VS, Gopinathan M. Reliability of determining vertical dimension of occlusion in complete dentures: a clinical study. J Indian Prosthodont Soc 2006;6(1):38-42.

20. McGee GF. Use of facial measurements in determining vertical dimension. J Am Dent Assoc 1947 Sep;35(5):342-350.

21. Silverman MM. Pre-extraction records to avoid premature aging of the denture patient. J Prosthet Dent 1955 Jul;5(4):465-476.

22. Smith ES. Vertical dimension and centric jaw relation in complete denture construction. J Prosthet Dent 1958 Jan;8(1):31-34.

23. Nag A, Nag PK, Desai H. Hand anthropometry of Indian women. Indian J Med Res 2003 Jun;117:260-269.

24. Tavano KT, Seraidarian PI, de Oliveira DD, Jansen WC. Determination of vertical dimension of occlusion in dentate patients by cephalometric analysis - pilot study. Gerodontology 2012 Jun;29(2):e297-e305.

25. Delić Z, Simunović-Soskić M, Perinić-Grzić R, Vukovojac S, Rajić Z, Kuna T, Kuna T. Evaluation of craniometric methods for determination of vertical dimension of occlusion. Coll Antropol 2000 Jul;24 (Suppl 1):31-35. 